IZA DP No. 7855

A Demographic Dividend for Sub-Saharan Africa: Source, Magnitude, and Realization

David E. Bloom Salal Humair Larry Rosenberg

December 2013
J.P. Sevilla

James Trussell 


\title{
A Demographic Dividend for Sub-Saharan Africa: Source, Magnitude, and Realization
}

\author{
David E. Bloom \\ Harvard School of Public Health \\ and IZA \\ Salal Humair \\ Harvard School of Public Health \\ Larry Rosenberg \\ Harvard School of Public Health
}

\author{
J.P. Sevilla \\ George Mason School of Law \\ James Trussell \\ Princeton University \\ and Hull York Medical School
}

\section{Discussion Paper No. 7855 \\ December 2013}

\author{
IZA \\ P.O. Box 7240 \\ 53072 Bonn \\ Germany \\ Phone: $+49-228-3894-0$ \\ Fax: +49-228-3894-180 \\ E-mail: iza@iza.org
}

\begin{abstract}
Any opinions expressed here are those of the author(s) and not those of IZA. Research published in this series may include views on policy, but the institute itself takes no institutional policy positions. The IZA research network is committed to the IZA Guiding Principles of Research Integrity.

The Institute for the Study of Labor (IZA) in Bonn is a local and virtual international research center and a place of communication between science, politics and business. IZA is an independent nonprofit organization supported by Deutsche Post Foundation. The center is associated with the University of Bonn and offers a stimulating research environment through its international network, workshops and conferences, data service, project support, research visits and doctoral program. IZA engages in (i) original and internationally competitive research in all fields of labor economics, (ii) development of policy concepts, and (iii) dissemination of research results and concepts to the interested public.
\end{abstract}

IZA Discussion Papers often represent preliminary work and are circulated to encourage discussion. Citation of such a paper should account for its provisional character. A revised version may be available directly from the author. 


\title{
ABSTRACT
}

\section{A Demographic Dividend for Sub-Saharan Africa: Source, Magnitude, and Realization}

\begin{abstract}
Managing rapid population growth and spurring economic growth are among the most pressing policy challenges for Sub-Saharan Africa. We discuss the links between them and investigate the potential of family planning programs to address these challenges. Specifically, we estimate the impact of family planning programs on income per capita that can arise via the demographic dividend (DD), a boost to per capita income that operates through a chain of causality related to declining fertility. We develop a model to determine the impact of "meeting unmet need" (MUN) for modern contraceptive methods on fertility and hence on the population age structure in the coming years. We also estimate empirically the DD that has been observed in other countries, using a cross-country regression with panel data covering 40 years. Using the age structure projected by MUN and the empirical estimates of the DD, we estimate the potential for additional economic growth in Kenya, Nigeria, and Senegal. We find that in 2030, these countries can enjoy an increase in per capita income of $8-13 \%$ by meeting one-third of their unmet need for modern contraception and can enjoy a 31-65\% higher income per capita by meeting all of the unmet need. By 2050 , these ranges become $13-22 \%$ and $47-87 \%$ respectively. We discuss the policy implications of our findings.
\end{abstract}

JEL Classification: J11, J13, O55

Keywords: aging, health care, labor studies

Corresponding author:

David E. Bloom

Department of Global Health and Population

Harvard School of Public Health

665 Huntington Avenue

Building I 12th Floor, Suite 1202

Boston, Massachusetts 02115

USA

E-mail: dbloom@hsph.harvard.edu

\footnotetext{
* This research was supported by a grant from the Bill and Melinda Gates Foundation (DB, SH, LR, JS). It was also supported in part by the Eunice Kennedy Shriver National Institute of Child Health and Human Development grant for Infrastructure for Population Research at Princeton University, Grant R24HD047879 (JT).
} 


\section{Introduction}

The population of Sub-Saharan Africa is growing more rapidly than that in any other region of the world. The United Nations (UN) Population Division medium-fertility scenario projects that Sub-Saharan Africa's population will more than double in less than four decades, from 901 million today to 2.07 billion in 2050 . The region will account for roughly half of global population growth till 2050, raising the share of world's population that belongs to Sub-Saharan Africa to $22 \%$ by then, compared to $13 \%$ today.

Given the low standard of living throughout the region, in terms of health, education, housing, and other factors, rapid population growth raises questions about the region's economic prospects. With governments that have historically had difficulty in promoting economic growth, worries abound about the feasibility of improving the lives of Africans.

The implications of such population growth are the subject of controversy and are the continuation of a historical debate that has been going on for hundreds of years. Thomas Malthus, in his 1798 treatise, An Essay on the Principle of Population, predicted that population would inevitably grow faster than food supply and that humanity was therefore doomed to misery. Others have argued that large populations are important for countries striving to gain a place on the world stage and for economic advancement in general. However, for a long time, researchers found no measurable relationship between the rate of population growth and economic advancement. That understanding changed in the last two decades. We now have evidence of a link between population growth and economic advancement, but the nature of that link is more nuanced than in the earlier arguments.

Consider Sub-Saharan Africa. The UN population projections are not the only path this region can follow. If the fertility rate (number of children per woman over her lifetime) in Sub-Saharan Africa were just half a child lower than the rate in the UN medium-fertility scenario, the region would have 1.84 billion people in 2050 - about 230 million fewer than in the medium-fertility scenario.

Perhaps even more important, if the fertility rate were lower by just half a child, the age distribution of Sub-Saharan Africa would shift. At present, the ratio of those between ages 15 and 64 (what demographers typically consider the "working-age population") ${ }^{1}$ and the nonworking-age population is 1.17 - the lowest of any region in the world. In the medium-fertility scenario, this ratio is projected to rise to 1.59 in 2050; the corresponding figure in the low-fertility scenario is $1.80 .^{2}$ Figure 1 shows the ratio of the working-age to non-working-age population in Sub-Saharan Africa and the three countries we focus on this paper, with data from 1950 to the present and projections through 2050. The importance of this ratio, which is projected to rise rapidly in the next few decades, is discussed below.

\footnotetext{
${ }^{1}$ The conclusions presented in the paper would not be substantially different if we used a somewhat different age range for "working age".

${ }^{2}$ Although this increase would matter, as explained below, it must be acknowledged that this change is dwarfed by the pace at which this indicator increased in East Asia and the Pacific - from 1.27 in 1975 to 2.45 today - a spurt that took place primarily because of that region's rapid fertility decline.
} 
Figure 1: Longitudinal change in the ratio of working-age to non-working-age population

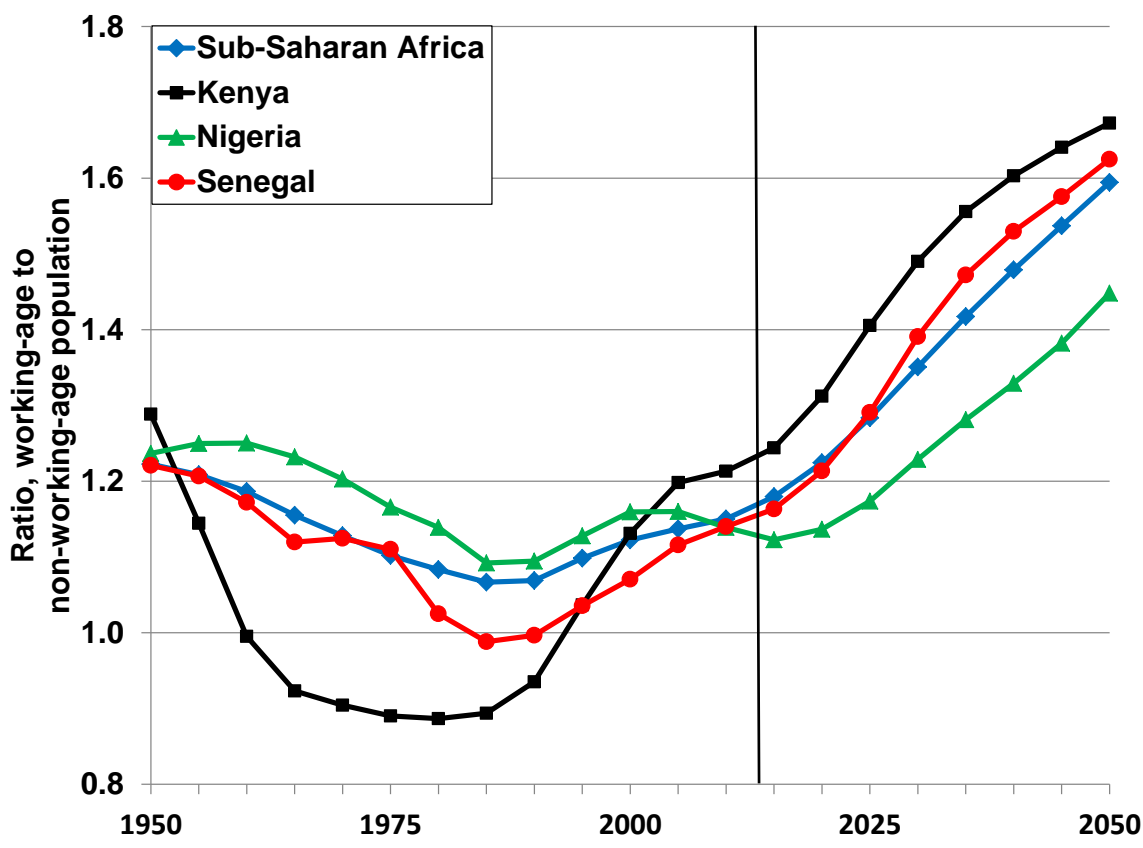

Source: UN Population Division (2013). World Population Prospects, the 2012 Revision.

Why do these population figures, and the different fertility scenarios, matter? How might lowering the fertility rate lead to more rapid economic growth? The answer lies in a concept known as the "demographic dividend".

\section{What is the demographic dividend?}

The demographic dividend is the economic growth potential that is created by favorable shifts in the age distribution of the population. For most low- and middle-income countries, changes in population age structure stem from a phenomenon known as the demographic transition, which is as central to the field of demography as supply and demand is to economics.

Figure 2 is a graphical representation of the demographic transition. This is a descriptive model that refers to the nearly ubiquitous change developing countries make from a regime of high fertility and high mortality to one of low fertility and low mortality. But these changes tend to happen in an asynchronous fashion, with death rates declining first and birth rates following suit later. The result of the lag is a transitional period of population growth, which has traditionally been the main focus of economists interested in demographics. 
Figure 2: The demographic transition: High fertility and mortality transitioning to low fertility and mortality, with consequent temporary high rate of population growth
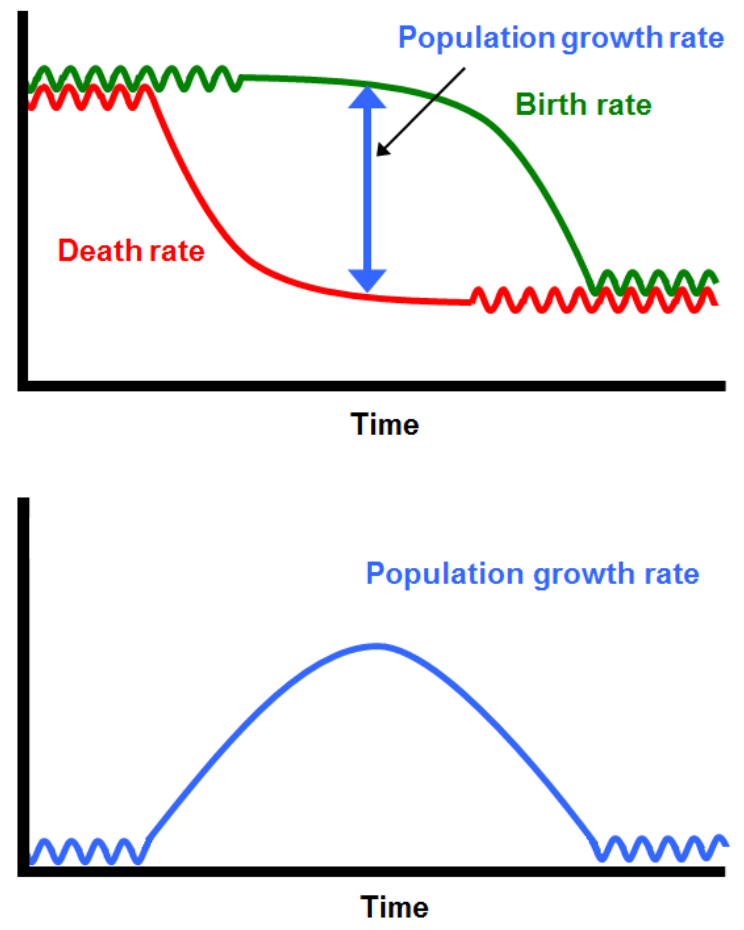

Mortality declines in high-mortality populations are mainly associated with declines in infant and child mortality (due typically to the spread of vaccines, antibiotics, safe water, sanitation, etc.). That mortality decline causes a baby boom - not the usual one in which there are more births, but one in which more babies that are born actually survive. The baby boom ends as fertility subsequently declines - which it invariably does as couples realize that fewer births are needed to reach their targets for surviving children, and as those targets themselves are moderated as the development process proceeds.

Baby booms are very consequential economically, because a society with many children requires significant resources for food, clothing, housing, medical care, and schooling. Those resources must be diverted from other uses such as building factories, creating infrastructure, and investing in R\&D. And that diversion of resources tends to slow the process of economic growth, as conventionally measured.

But the baby boom will invariably reach the working ages within a period of $15-25$ years. And when that happens the economic situation changes as the productive capacity of the economy expands on a per capita basis - most centrally because the share of the population that is of working age increases, albeit temporarily. The economy expands on a per capita basis because of the expansion of labor supply as the boomers reach working ages (i.e., output per capita rises, holding output per worker fixed, because there are more workers per capita) and as women's labor force participation increases with declining fertility. Potential output also grows because the working ages are also the prime years for savings, which are key to capital accumulation and technological innovation. Savings get a further boost as old-age mortality declines in the latter phases of the demographic transition. 
In summary, mortality declines at the beginning of the demographic transition catalyze fertility declines. And fertility declines are potent drivers of economically consequential changes in the age structure of the population.

\section{Empirical evidence on the demographic dividend}

The description of the demographic dividend above makes clear the potential economic importance of the relative size of a country's working-age population. During the demographic transition, the working-age share of the population increases when fertility falls (declines that can happen, in part, because of the effect of family planning programs). When the working-age share is high, economic growth may be potentiated - this effect is the demographic dividend.

The evidence for the presence of the demographic dividend comes from, among other examples, the rise of East Asian economies in the 1960s, 1970s, and 1980s, (Bloom and Williamson 1998) and more recent analysis of the economic performance of Asia in the 1990s (Bloom and Finlay 2009). The dividend may be quite large; it is estimated to account for up to one-third of the increase in incomes seen in East Asia between 1965 and 1990 (Bloom and Williamson 1998; Bloom, Canning and Malaney 2000; Bloom and Canning 2008). An early effort to examine the possibility of a demographic dividend for Africa is (Bloom and Sachs 1998), who find that the countries of Sub-Saharan Africa have the potential to reap a sizable demographic dividend. Bloom, Canning, Fink and Finlay (Bloom et al. 2007) find that African economies follow the same principles as those of other countries and that with enabling policies in place, Sub-Saharan Africa should be able to realize a demographic dividend. Canning (Canning 2013) provides a more up to date treatment of the demographic dividend in Africa.

Perhaps the easiest way to see the dividend in action is to compare the economically and demographically most extreme regions of the developing world: East Asia / Pacific and SubSaharan Africa. For the developing countries of these two regions, Figure 3 shows GDP/capita from 1960 through 2010 and the ratio of working-age to non-working age population (with actual data through the present and projected data through 2050). 
Figure 3: Developing Countries of East Asia \& the Pacific, and of Sub-Saharan Africa: Correspondence between demographic and economic indicators

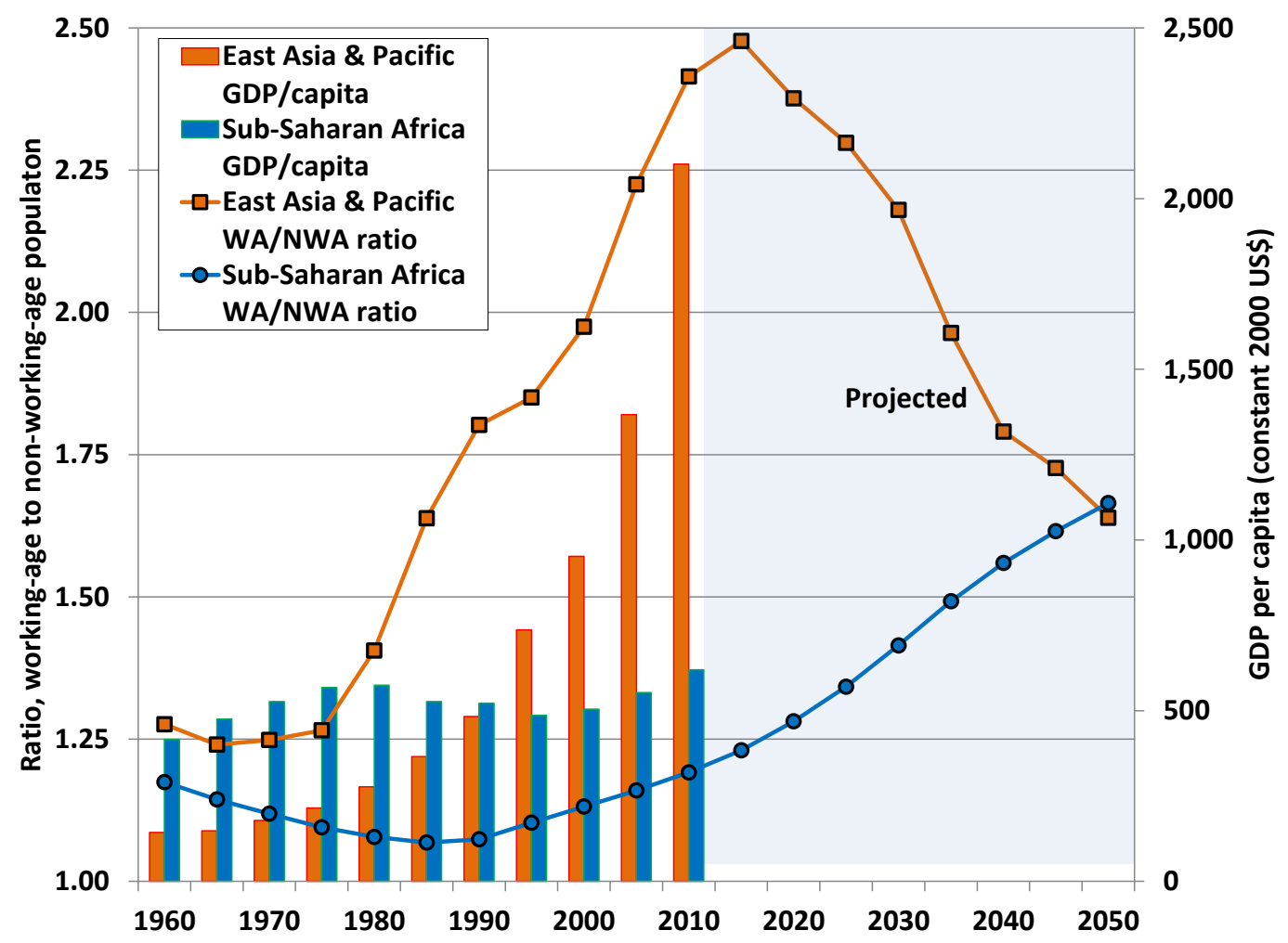

Source: (United Nations 2011; World Bank 2013) The source specifies the developing countries in each region.

The economies of Sub-Saharan Africa grew slowly in the first several decades shown here; nevertheless, East Asia did not catch up to Sub-Saharan Africa until around 1990. But then, as is widely known, the economies of East Asia took off, while those of Sub-Saharan Africa continued to stagnate. Now, East Asia's income per capita is more than triple that of SubSaharan Africa.

The path of fertility rate decline was also distinctly different in the two regions, with East Asia's rate falling extremely rapidly and Sub-Saharan Africa's quite slowly. Fertility in Sub-Saharan Africa in 2010 stood at about the same level as in East Asia in the early 1970s (5 children per woman).

Falling fertility raises the share of the population that is of working age, and Figure 3 shows the consequences for the age structure in the two regions. The ratio of working-age to non-workingage population soared in East Asia, beginning in the 1980s, while it began to rise in SubSaharan Africa only the 1990s, and then only slowly. In fact, the ratio of working-age to nonworking-age population has been lower in Sub-Saharan Africa than in East Asia throughout the period shown, reflecting a relatively high burden of youth dependency, due to a long history of consistently high fertility. By contrast, East Asia has had the fastest and most pronounced demographic transition in history. In 1950, the difference in the working-age to non-working-age ratio between East Asia and Sub-Saharan Africa was fairly small, but it grew dramatically from 1975 on. And today, East Asia has roughly 2.4 workers for every non-worker, much more than Sub-Saharan Africa's 1.2 workers per non-worker. For a household, such a differential will tend 
to translate into a commensurately large increase in income. And this intuition about individual households essentially aggregates to the level of countries and regions.

Figure 3 shows that demographic changes have closely tracked income growth in both regions and offers a compelling explanation for East Asia overtaking Sub-Saharan Africa economically. There are, of course, many other determinants of income growth that are not reflected in this graph, and economists have investigated them in considerable depth. But even with those determinants taken into account, the basic narrative about the economic impact of demographics remains qualitatively unchanged. It is also important to note that about 2 percentage points of annual per capita income growth in East Asia can, over the past few decades, be attributed to its favorable demographics.

Figure 3 also shows the United Nations' demographic projections for the two regions. East Asia's working-age to non-working-age ratio is slated to plummet, while Sub-Saharan Africa's is expected to rise. These changes may influence economic outcomes in the two regions.

A comparison of the demographic and economic history of Indonesia and Nigeria offers a similar tale. Both countries are populous, major oil exporters with large Muslim populations, so they make an apt pair for comparison.

Figure 4 shows the change in the ratio of working-age to non-working-age population in Indonesia and Nigeria. The two countries were similar in this regard in 1960, and in both the ratio fell in the ensuing years. But as Indonesia's fertility rate began to decline (while Nigeria's did not), its ratio rose rapidly. In Nigeria, meanwhile, the ratio has only recently begun to rise, in response to a slow fertility rate decline. The graph also displays the trend in GDP per capita of the two countries. Nigeria was slightly ahead of Indonesia in 1960, but Indonesia's GDP per capita is now roughly double Nigeria's. As with the example of East Asia and Sub-Saharan Africa, it is evident that demographic change closely tracks income growth in both Nigeria and Indonesia. 
Figure 4: Indonesia and Nigeria: Correspondence between demographic and economic indicators

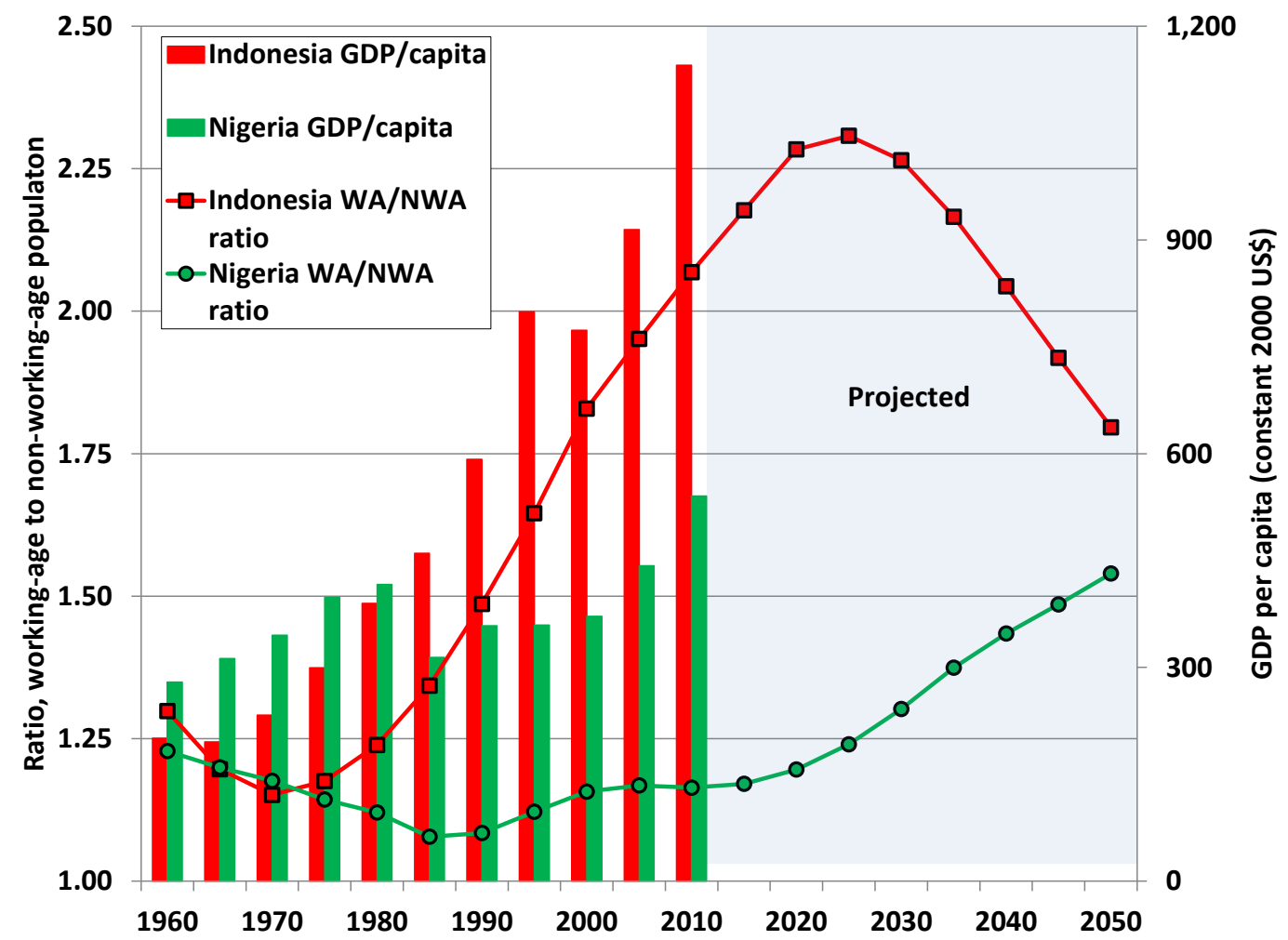

Source: (World Bank 2010; United Nations 2011)

The economic successes of East Asia and Indonesia are not coincidentally related to demographics. Rather, they seem to be causally related to East Asia's and Indonesia's fertility transitions, which led their age structures to evolve in a way that were highly favorable for economic growth, allowing these countries to harness a demographic dividend. In much of SubSaharan Africa, this fertility transition has only begun to take place.

Of course, the demographic dividend is not the sole explanation for the differing economic trajectories of East Asia (and Indonesia), on the one hand, and Sub-Saharan Africa (and Nigeria), on the other. But this explanation is intuitively plausible, theoretically sound, and consistent with the data.

\section{The effect of investments in family planning programs on fertility}

The economic consequences of demographic transitions raise several natural questions. Two basic questions are: can Sub-Saharan Africa lower its fertility, and, if so, what economic benefits can it obtain?

One avenue for reducing fertility is family planning programs. Although some have argued otherwise, on balance, the evidence suggests that family planning programs can help to lower fertility appreciably, but only if they are well designed with respect to the cultural and social context, and well implemented. 


\section{Sorting out the conflicting views and evidence}

Many demographers think that binding constraints in the supply of contraceptives account for elevated rates of fertility. They attribute a high share of fertility decline to the expansion of family planning programs, e.g. (Cleland et al. 1994; Bongaarts and Sinding 2011). By contrast, some economists argue (Pritchett 1994) that family planning has no independent effect on fertility, and that desired fertility is key, along with its determinants: economic advances, expansions in girls' education (Lutz and KC 2011), and greater economic opportunities for women, etc. According to this view, all family planning does is enable the alignment of desired and actual fertility, e.g. see (Gertler and Molyneaux 1994) for a study of Indonesia, and (Miller 2010) for a study of Colombia - both studies find that family planning accounts for a very small share of fertility decline. But providing family planning services does more than just prevent births: a wellthought-out program can help change norms regarding family size and thereby affect desired fertility.

In general, the mere observation of a negative correlation between the contraceptive prevalence rate and fertility does not imply that increasing the supply of contraceptives will lead to a decline in births. Various other factors play a major role in a woman's (or a family's) decision to use contraceptives and in the ability to use them effectively. Cultural norms or religious beliefs may weigh against the use of some or all contraceptives; husbands (or their mothers) may not want wives to use contraceptives at all; fear of side effects can be a major stumbling block; and misinformation about proper use can of course render them ineffective. These impediments are relevant to the observation that there are $200+$ million women who have unmet need for family planning - meaning that they do not want to have children in the near future, that they are in a union with a man, and that they are at risk of becoming pregnant because they are not using contraceptives. Many demographers believe that if these women were offered family planning services, many or most would all use contraceptives and their fertility rate would decline.

What seems to be key here is that if a family planning program is to work, it has to be well designed and implemented, meaning in particular that it must effectively take into account the exact setting in which it will be used. For example, experience and studies in West Africa suggest that provision of family planning services alone is not necessarily what appeals to families in high-fertility settings; in a study known as the Navrongo experiment in Ghana, family planning services were well integrated with community health services, and that integration seems to have been a key to success (Nyonator et al. 2005). This experiment is particularly notable because it was a randomized trial and it found that the intervention led to a decline in fertility of one child per woman.

Another very strong piece of evidence in support of the view that family planning programs can reduce fertility is the Matlab program, which was carried out in Bangladesh between 1977 and 1996. In that program, participating villages were randomized, with some receiving family planning services and others not. A careful examination of the Matlab data by Yale economist T. Paul Schultz recently concluded that: "The family planning program is associated with a 10-15 percent decrease in fertility and population growth for two decades" (Schultz 2009). Economists like Lant Pritchett dismiss these results as being inapplicable to countries as a whole, because the Matlab effort was so expensive and could not be extended to a whole country. That may be so, but at the very least Matlab demonstrates that family planning programs can have an effect on fertility.

The bottom line is while the evidence base for the effectiveness of family planning in reducing fertility has produced equivocal inferences, it appears that family planning programs can have a big impact on fertility (i.e., a reduction of 1.0 in the total fertility rate (TFR)) if they are well 
designed and well implemented (e.g., including appropriate counseling and matching the type of contraceptive to participants' needs) and if they fit well with the social and cultural context in which they are carried out.

\section{Potential size of the economic benefits of meeting unmet need}

If family planning programs impact fertility decline, the next question is: what economic benefits might result from well-designed and well-implemented family planning programs?

One simple way to estimate economic benefits is to estimate the health benefits of family planning programs (e.g., reduction in maternal and infant mortality or morbidity), and then use various measures (e.g., the value of a life saved or disability adjusted life years) to compute the resulting economic benefits. This is the approach reported in the recent State of the World Population 2012 report (UNFPA 2012) of the United Nations Population Fund (UNFPA), which also discusses, qualitatively, the range of potential economic benefits from investment in family planning programs.

Here we present a different approach that directly estimates the impact of family planning on income per capita. More specifically, we estimate the impact of "meeting unmet need" (MUN) for modern methods of family planning - that is, of raising the uptake of modern contraception among the women of reproductive age who are in marriage or in union, who currently do not wish to be pregnant, and who are not using modern contraception. It is also important to note that the per capita income increases we estimate are only a part of the total package of benefits resulting from family planning programs. Other benefits include reduced maternal and infant mortality, unsafe abortions, and unintended pregnancies (Ahmed et al. 2012; Singh and Darroch 2012).

The methodology for the research carried out for this paper is described in detail in the appendix and integrates new research with well-established methods for estimating the demographic dividend (Bloom and Williamson 1998; Bloom, Canning and Malaney 2000; Bloom, Canning and Sevilla 2003; Bloom and Canning 2008; Bloom 2011).

We present the results for three Sub-Saharan countries (Kenya, Nigeria and Senegal) for multiple scenarios, where unmet need for contraceptives is met with different degrees of success. ${ }^{3}$ For each country, we explore: when none of the unmet need for contraception is met, which serves as our baseline (B), when a low (33\%) level of unmet need is met $(\mathrm{L})$, a moderate level $(67 \%)$ of unmet need is met $(M)$, and a high level $(100 \%)$ of unmet need is met $(H){ }^{4}$

Figures 5-7 show how the primary driver of economic growth for the demographic dividend, the working-age share of the population, is substantially shifted under different MUN scenarios. For Kenya, for instance, the working-age share of the population could increase over the baseline (in 2025) by as much as 3 percentage points over $2005-2050$ for the $L$ scenario (33\% of unmet

\footnotetext{
${ }^{3}$ These three countries represent three different rates of fertility decline to date. Nigeria has undergone the slowest change, with its TFR having declined minimally, from a peak of 6.8 children per woman in the late 1970 s to 6.0 today. Senegal's TFR has declined more rapidly, from a peak of 7.5 in the late 1970 s to 5.0 today. Kenya has seen the fastest reduction, from a peak of 8.1 in the early 1960 s (and a level of 7.6 in the late 1970 s) to 4.4 today.

${ }^{4}$ Although these criteria are somewhat arbitrary, they make sense: A minimally successful program might still reasonably be expected to achieve a one-third reduction in unmet need, whereas a reasonable goal for a moderately successful program would be a two-thirds reduction. We include the no-reduction and complete-reduction scenarios to show the full range of possibilities.
} 
need met), and by as much as 11 percentage points (in 2025) for the $\mathrm{H}$ scenario (100\% of unmet need met). Over 2005-2050, the maximum difference in working-age share between the $\mathrm{H}$ and $\mathrm{L}$ scenarios for Kenya would be around 8 percentage points. For other countries, the maximum differences in working-age share between $\mathrm{H}$ and $\mathrm{L} M U N$ scenarios are less than in Kenya, but still substantial (4\% and 5.7\% for Nigeria and Senegal respectively).

Figure 5: Working age-share of the population for Kenya under different MUN scenarios: B ( $0 \%$ of unmet need met), L ( $1 / 3^{\text {rd }}$ of unmet need met), M ( $2 / 3^{\text {rd }}$ of unmet need met), $H$ (all unmet need met).

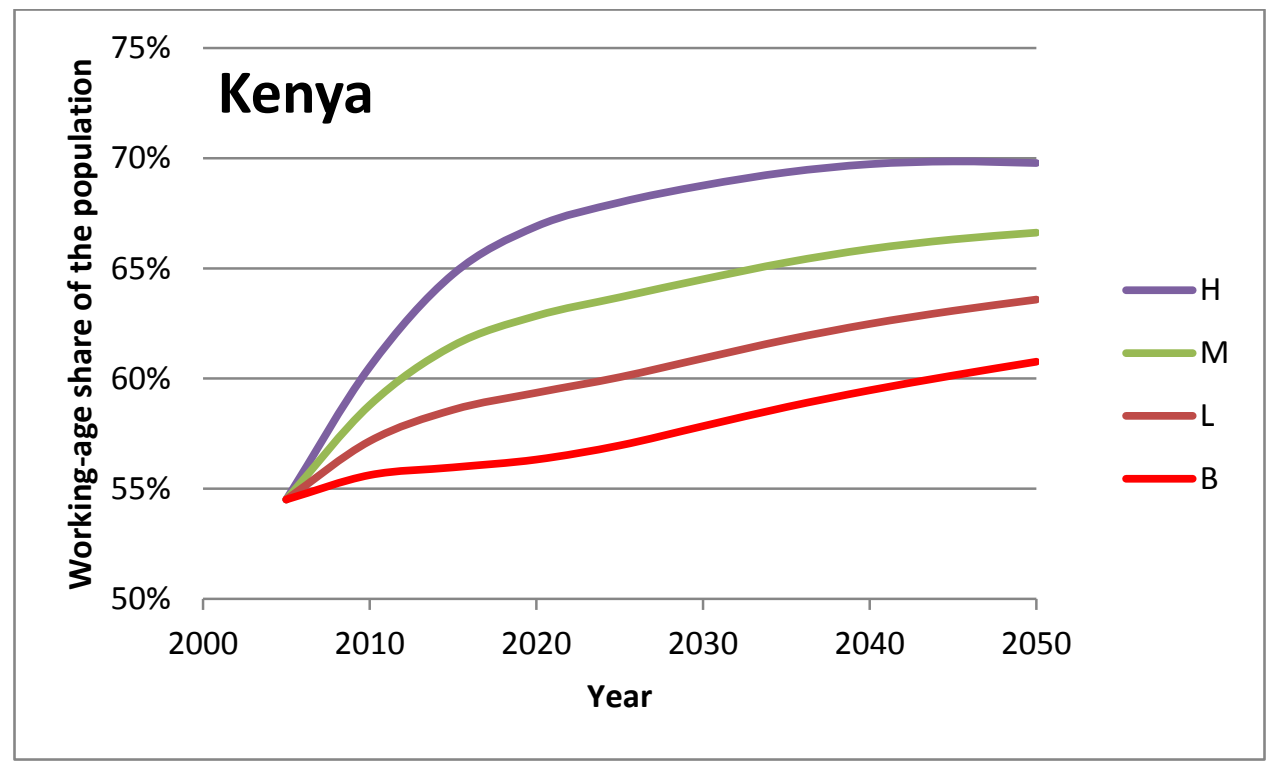

Figure 6: Working age-share of the population for Nigeria under different MUN scenarios: B ( $0 \%$ of unmet need met), L (1/3 ${ }^{\text {rd }}$ of unmet need met), $M\left(2 / 3^{\text {rd }}\right.$ of unmet need met), $H$ (all unmet need met).

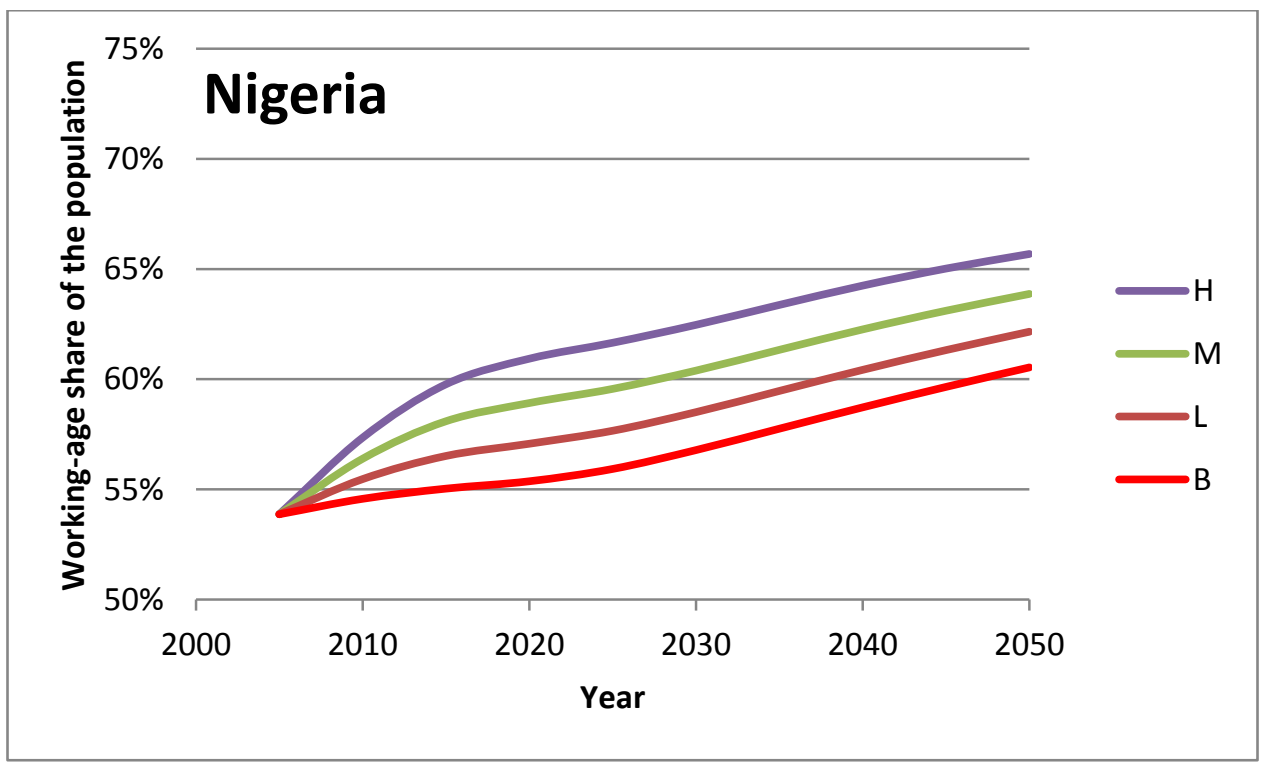


Figure 7: Working age-share of the population for Senegal under different MUN scenarios: B $(0 \%$ of unmet need met), $L\left(1 / 3^{\text {rd }}\right.$ of unmet need met), $M\left(2 / 3^{\text {rd }}\right.$ of unmet need met), $H$ (all unmet need met).

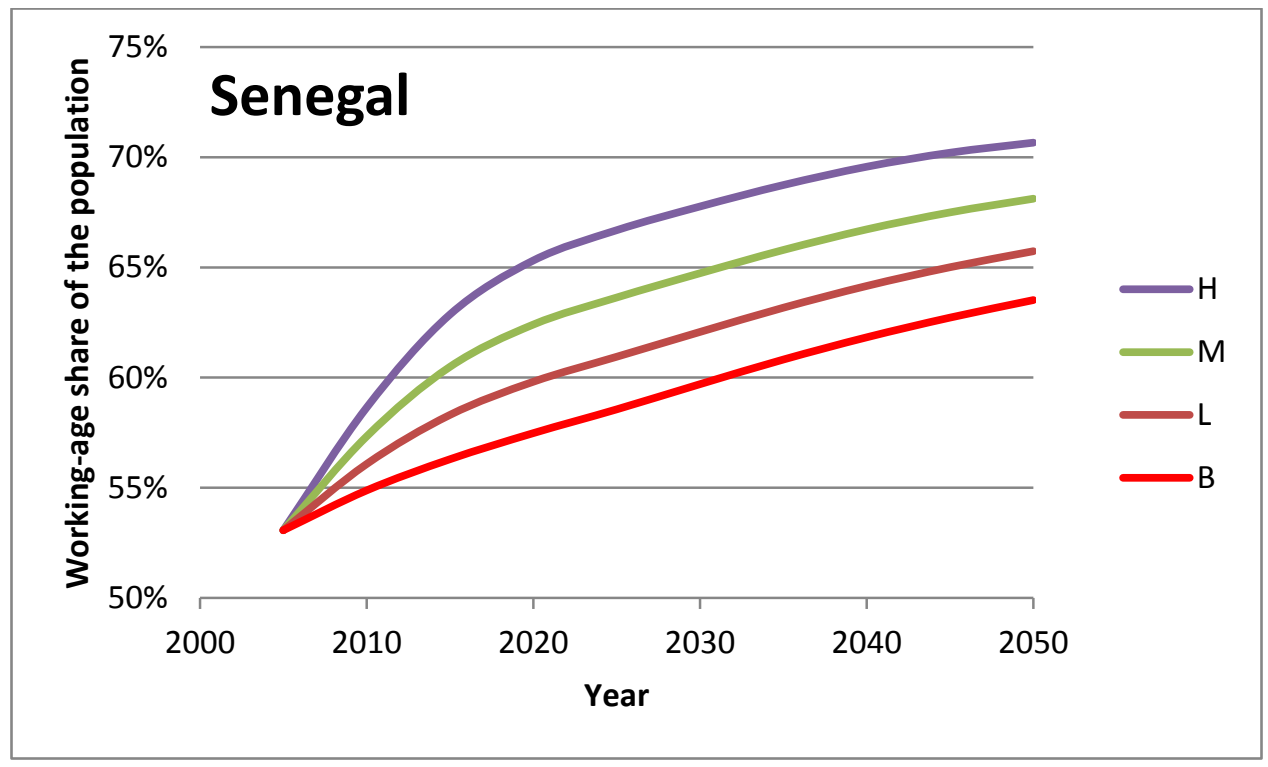

Figures 8-10 show projected GDP per capita for the baseline and three MUN scenarios. The amounts shown are real per capita GDP in year 2000 international dollars.

Figure 8: Projected per capita income for Kenya under different MUN scenarios: B ( $0 \%$ of unmet need met), L ( $1 / 3^{\text {rd }}$ of unmet need met), $M\left(2 / 3^{\text {rd }}\right.$ of unmet need met), $H$ (all unmet need met).

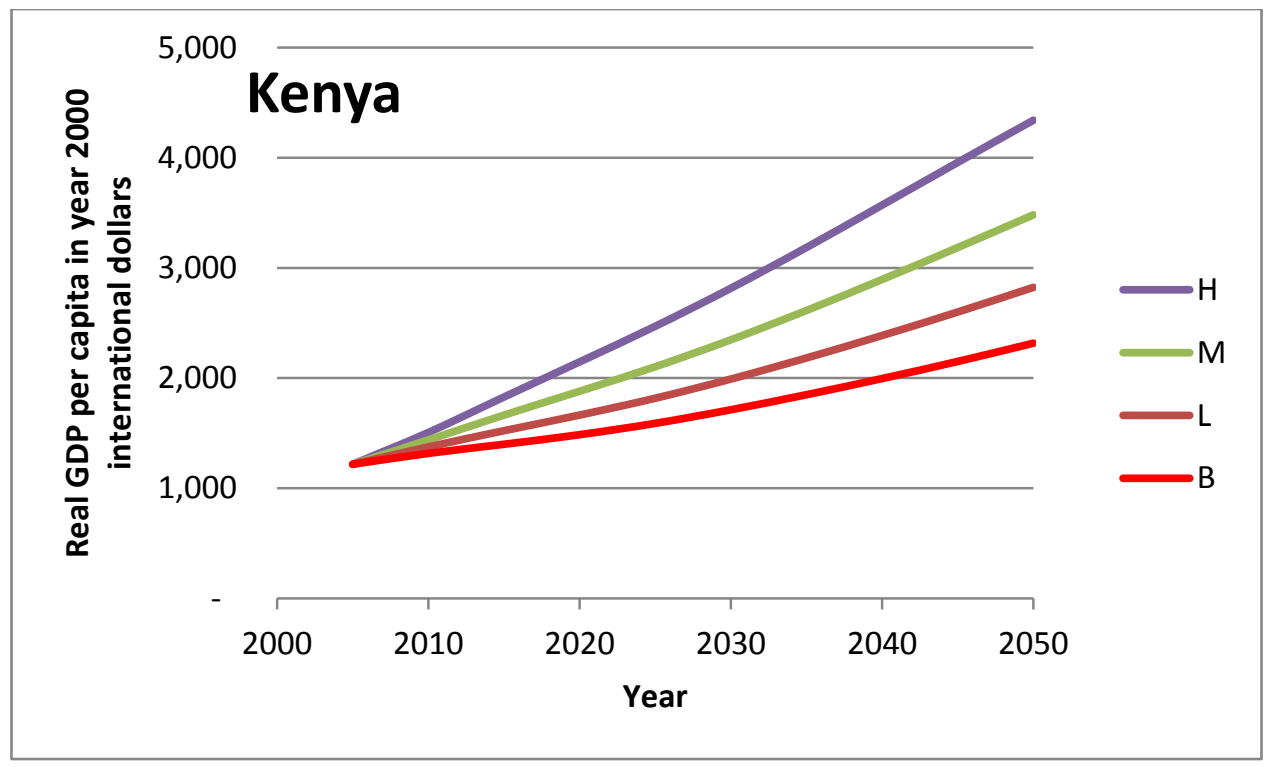


Figure 9: Projected per capita income for Nigeria under different MUN scenarios: B $(0 \%$ of unmet need met), $L\left(1 / 3^{\text {rd }}\right.$ of unmet need met), $M\left(2 / 3^{\text {rd }}\right.$ of unmet need met), $H$ (all unmet need met).

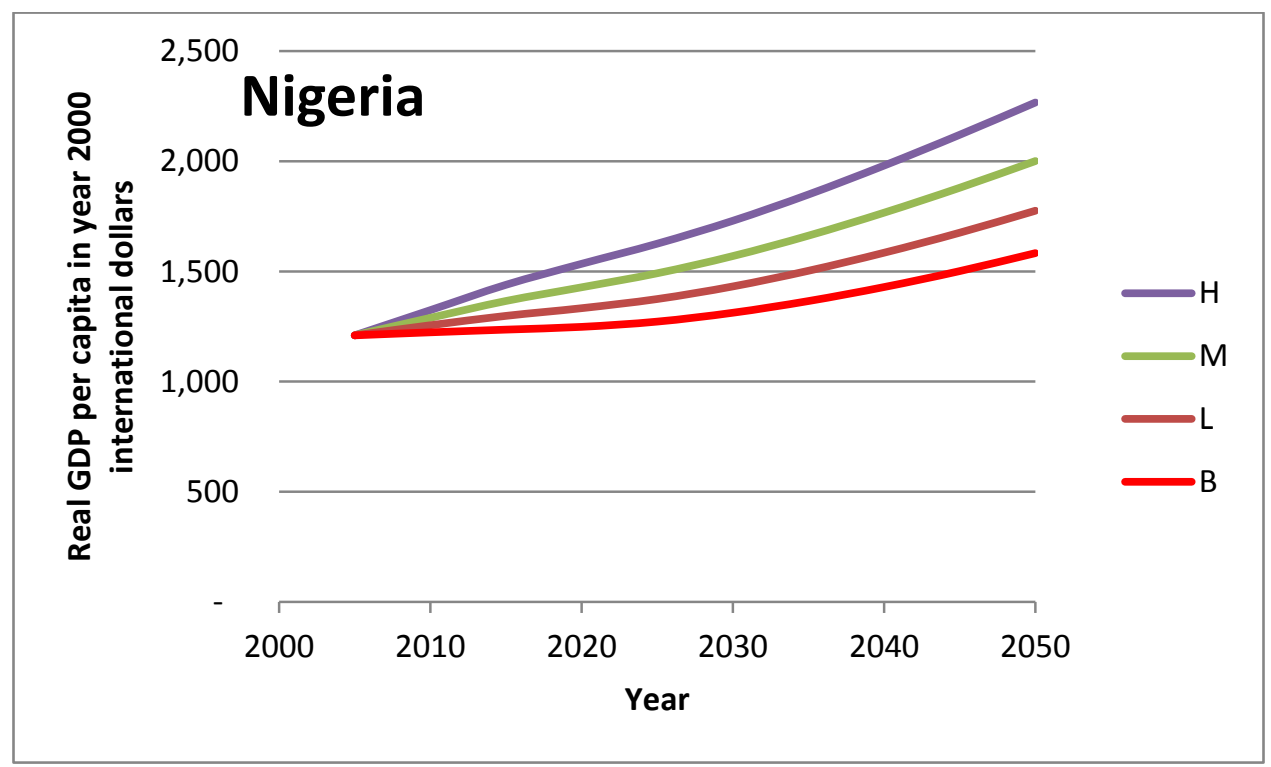

Figure 10: Projected per capita income for Senegal under different MUN scenarios: B ( $0 \%$ of unmet need met), L (1/3 ${ }^{\text {rd }}$ of unmet need met), M ( $2 / 3^{\text {rd }}$ of unmet need met), $H$ (all unmet need met).

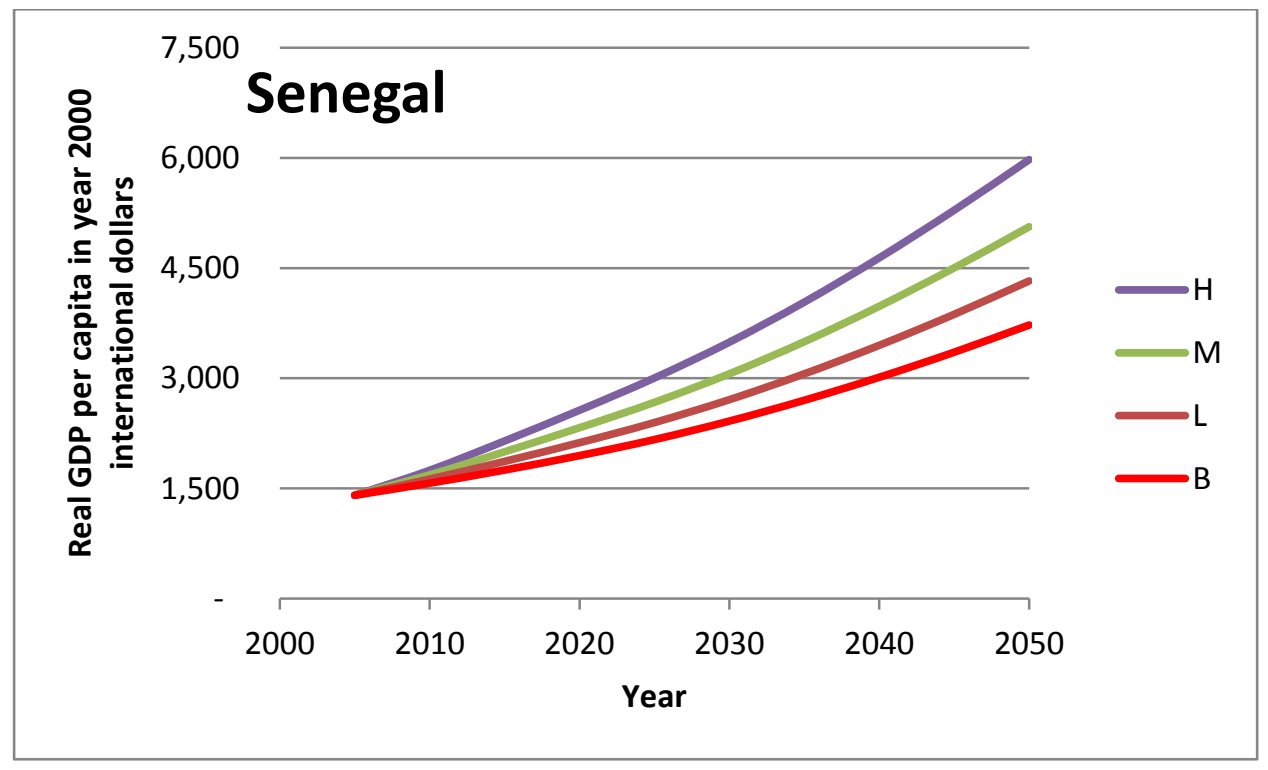

Table 1 shows a snapshot of these figures in years 2030 and 2050. The table shows that in 2030 , Kenya can enjoy a $16 \%$ increase in per capita income over the baseline by meeting onethird of its unmet need, and a $64 \%$ increase over the baseline by meeting all of its unmet need. Even Nigeria (the country obtaining the lowest percentage increase in per capita income over the baseline) can enjoy $9 \%$ (by meeting one-third of unmet need) and $32 \%$ (by meeting all of its 
unmet need) more income per capita by 2030 , and $12 \%$ and $43 \%$ more income per capita by 2050 under these scenarios.

Table 1: Estimated income per capita in 2030 and 2050 for each country under different MUN scenarios.

\begin{tabular}{llllll}
\hline Country & Year & B & L & M & H \\
\hline Kenya & 2030 & 1,710 & 1,990 & 2,340 & 2,810 \\
Kenya & 2050 & 2,310 & 2,820 & 3,480 & 4,340 \\
Nigeria & 2030 & 1,310 & 1,430 & 1,560 & 1,720 \\
Nigeria & 2050 & 1,580 & 1,770 & 2,000 & 2,260 \\
Senegal & 2030 & 2,410 & 2,700 & 3,060 & 3,490 \\
Senegal & 2050 & 3,720 & 4,320 & 5,060 & 5,970 \\
\hline
\end{tabular}

We also observe that both Senegal and Kenya enjoy higher levels and rates of growth in per capita income relative to Nigeria. This finding results from Senegal's superior life expectancy relative to Nigeria, and from Kenya's superior life expectancy and institutional quality relative to Nigeria.

Table 2 facilitates comparison of the different per capita income trends under different MUN scenarios by showing the present discounted value (PDV), discounted back to 2005, using different discount rates.

Table 2: Estimated present discounted value (PDV) of income per capita (discounted to 2005) from 2005-2030 and 2005-2050 under different MUN scenarios, shown for $3 \%$, $6 \%$, and $0 \%$ discounting.

PDV of income per capita through 2030 and 2050 (discount rate in parentheses)

\begin{tabular}{|c|c|c|c|c|c|c|c|}
\hline Country & $\begin{array}{r}\text { MUN } \\
\text { scenario }\end{array}$ & $2030(3 \%)$ & $2050(3 \%)$ & $2030(6 \%)$ & $2050(6 \%)$ & $2030(0 \%)$ & $2050(0 \%)$ \\
\hline Kenya & B & 25,300 & 39,600 & 18,700 & 24,200 & 36,000 & 75,700 \\
\hline Kenya & $L$ & 27,500 & 44,500 & 20,200 & 26,700 & 39,400 & 86,900 \\
\hline Kenya & $M$ & 30,100 & 50,700 & 21,900 & 29,700 & 43,700 & 101,100 \\
\hline Kenya & $\mathrm{H}$ & 33,300 & 58,600 & 24,000 & 33,500 & 48,900 & 119,500 \\
\hline Nigeria & B & 22,200 & 32,600 & 16,700 & 20,700 & 31,100 & 59,700 \\
\hline Nigeria & L & 23,300 & 34,700 & 17,400 & 21,800 & 32,800 & 64,400 \\
\hline Nigeria & $M$ & 24,400 & 37,200 & 18,200 & 23,000 & 34,600 & 69,800 \\
\hline Nigeria & $\mathrm{H}$ & 25,700 & 40,000 & 19,000 & 24,500 & 36,600 & 76,100 \\
\hline Senegal & B & 32,000 & 53,500 & 23,400 & 31,600 & 46,100 & 106,100 \\
\hline Senegal & $\mathrm{L}$ & 34,200 & 58,700 & 24,800 & 34,100 & 49,600 & 118,200 \\
\hline Senegal & $M$ & 36,700 & 64,900 & 26,500 & 37,100 & 53,600 & 132,700 \\
\hline Senegal & $\mathrm{H}$ & 39,600 & 72,400 & 28,300 & 40,700 & 58,300 & 150,400 \\
\hline
\end{tabular}


Table 3 shows the differences in the PDV of per capita income in 2030 and 2050 between the $\mathrm{H}$ and L MUN scenarios. At 3\% discounting, for both Kenya and Senegal, these differences are more than \$5,000 in 2030 and approximately $\$ 14,000$ in 2050.

Table 3: Estimated difference in present discounted value (PDV) of the income per capita between the $\mathrm{H}(100 \%$ of unmet need met) and L (33\% of unmet need met) MUN scenarios.

\begin{tabular}{lrrr|rr} 
& \multicolumn{4}{c}{ Difference in PDV between H and L scenarios } \\
\cline { 2 - 6 } Country & Year & $\mathbf{2 0 3 0}(\mathbf{3 \% )}$ & $\mathbf{2 0 5 0}(\mathbf{3 \% )}$ & $\mathbf{2 0 3 0} \mathbf{6 \% )}$ & $\mathbf{2 0 5 0} \mathbf{( 6 \% )}$ \\
\hline Kenya & 2005 & 5,800 & 14,000 & 3,700 & 6,800 \\
Nigeria & 2005 & 2,400 & 5,200 & 1,600 & 2,600 \\
Senegal & 2005 & 5,300 & 13,600 & 3,400 & 6,500 \\
\hline
\end{tabular}

\section{Bringing about a demographic dividend: policy implications}

Without enabling policy interventions, the demographic dividend does not necessarily come about. Countries need to assess their progression through the demographic transition to determine what steps are most important in realizing the dividend.

Countries that are still in the very early stages of the demographic transition (such as some of those in Central and Western Africa, including Nigeria) need to focus on policies that will catalyze the transition. To do that, countries need to think about making wider and deeper investments in health. Such investments traditionally involve primary health care; safe water and sanitation, vaccines and drugs; and school lunch programs - all of which tend to improve child survival, which is the usual trigger for fertility decline.

Countries that are in the middle stages of the demographic transition (such as some in Southern Africa, but also including Kenya) need to focus on policies to accelerate the transition, which essentially means a policy to accelerate fertility decline. This typically involves the provision of family planning supplies and services, and the expansion of education and job opportunities for girls and women.

It is also important to note other pre-conditions for countries to capture the demographic dividend, since the gains from a change in age structure are not automatic (Bloom 2011). Realizing the demographic dividend requires first and foremost the creation of opportunity, in particular, the right mix of jobs that allow workers to contribute productively to the economy.

Job creation in turn requires sustained investment in human capital, e.g., education and health. Uneducated workers can typically engage in activities with a relatively low value added. Similarly, unhealthy workers are often limited in the energy and perseverance they can bring to a workplace. By contrast, workers who are well educated and healthy are much more able to contribute productively to a country's economy. They are more likely to attend work regularly and to be able to learn new skills and apply them reliably. The human capital that is embodied in educated, healthy individuals is invaluable for promoting rapid economic growth.

In Sub-Saharan Africa another factor comes into play: outmigration and brain drain. When a large number of educated individuals migrate to other countries where their skills may be more highly rewarded, the potential economic benefits of having an educated population are somewhat diminished. We cannot at present quantify the extent of this effect in Sub-Saharan Africa, but we do note one countervailing phenomenon - that emigrants very often send home 
remittances in sufficiently large amounts that they can add to gross national income and make a large positive difference in the welfare of recipient households.

Beyond health and education, other factors can facilitate realization of the demographic dividend, including good governance, strong institutions of various types, a carefully constructed trade policy, solid macroeconomic management, well-developed financial markets, good relations with neighboring countries, and absence of civil conflict and foreign wars. Also of note, the countries of East Asia were able to capitalize on their demographic changes in part because they focused on producing low-cost exports, which a portion of the working-age population was employed in producing.

The many challenges countries face in bringing about a demographic dividend are not insurmountable, but they do require well-chosen and well-implemented policies. Further, the attainment of, for example, good institutions, better education, and better health, are not just pre-requisites for realizing the demographic dividend, but for a range of other things on the path to development (e.g., human rights, social security, adaptability and sustainability of a society).

\section{Recapping: the connection between family planning programs and raising incomes}

Family planning programs, when implemented in a manner that is sensitive to local practices and local needs, can bring about lower fertility rates, in part by lowering desired fertility. When desired fertility falls and contraception is available, fewer children will be born. The previous, larger cohort of children, when they reach working age, will constitute a relatively large workingage cohort. If working-age individuals are healthy and well educated, and if policies are in place so that potential workers are in fact productively employed, the working-age cohort can produce more on a per-worker basis and on a per-person basis (compared with the past), thus raising income per capita. In addition, since working-age individuals typically save more than people at other ages, the national savings rate can increase. The extra savings can be channeled into new investment, thus further boosting economic growth.

This whole chain of events begins with lower fertility, which can be powerfully abetted by carefully designed family planning programs that are attuned to local circumstances and that provide contraception to those who want it. This is a powerful chain, since the potential consequence of greater use of contraception is higher incomes.

\section{Conclusion}

The demographic dividend - the one-time economic bonus that can arise, if conditions are right, from a decline in fertility rates - could matter a lot for Sub-Saharan Africa. Rapid population growth will doubtless bring great challenges, but lower fertility rates could usher in a higher share of working-age people in the population and thus, potentially, enormous economic benefits for the region.

For instance, our results show that meeting unmet need for modern contraceptives could substantially increase GDP per capita in Kenya, Nigeria, and Senegal. Summarizing these results:

- $\quad$ The impact of meeting unmet need on per capita income. In 2030, these three countries can enjoy an increase in per capita income of $8-13 \%$ over the baseline if they meet one- 
third of their unmet need, and can enjoy a 31-65\% higher income per capita if they meet all of their unmet need. By 2050, these ranges become $13-22 \%$ and $47-87 \%$ respectively.

- $\quad$ The difference in the discounted cumulative value of per capita income between meeting a smaller portion of unmet need (33\%) vs. meeting a larger portion of unmet need (100\%). At 3\% discounting, the increase in PDV of income between meeting a high level of unmet need and meeting a low level of unmet need by 2030 is between $\$ 2,400$ and $\$ 5,800$, with the difference for two of the countries above $\$ 5,000$. By 2050 , the difference in PDV is in the range $\$ 5,300-\$ 14,100$, with the difference for two of the countries above $\$ 13,500$.

Together, these results provide a strong argument for sustained investment in family planning programs in Africa. In fact, the economic justification is even stronger since the above results focus on only a small part of the total economic benefits. A broader focus would include other long-term effects of fertility reduction - such as improved mother and child health, which could lead to better cognition and better schooling - leading to, for instance, higher productivity, a higher lifetime income, and protection for families against catastrophic health incidents (UNFPA 2012).

International efforts in this sphere could help. As the world nears the 2015 deadline for meeting the MDGs, a searching question will be how to push MDG5 (reduction in maternal mortality and universal access to reproductive health) higher on the agenda of policy makers. With progress on MDG5 lagging well behind that of other MDGs, advocates for reproductive health may find a need not only to redouble but also refocus their efforts. In doing so, they may find economic arguments an increasingly valuable complement to their ethics- and human rights-based arguments for investing in reproductive health. The rights-based approach has been central to global family planning efforts, especially since 1994 (UNFPA 2012), and has led to important gains; but as policy makers seek to balance competing priorities in the face of mounting economic pressures, the value of economic arguments will increase.

With respect to a focus on reproductive health, the earliest signals regarding the post-2015 development agenda are not unambiguously positive. The June 2013 Report of the High-Level Panel of Eminent Persons on the Post-2015 Development Agenda, entitled, A New Global Partnership: Eradicate Poverty and Transform Economies Through Sustainable Development, does not emphasize the importance of reproductive health or of lowering fertility rates. It does include a paragraph on these topics (in its discussion of the proposed new Goal 4, "Ensure healthy lives", Section d, "Ensure universal sexual and reproductive health and rights"), but does not suggest that they could be of overriding importance in reducing poverty and does not mention them in relationship to economic growth.

Of course, speeding social and economic development is a broad undertaking, and lowering fertility is one of numerous means that countries can adopt in pursuit of these goals. As noted above, a large and diverse set of factors can affect the pace of economic growth. Improving education can be particularly important, as educated individuals are more likely to be able to contribute productively to a growing economy. And in addition to the factors listed earlier, we should add environmental sustainability as an important consideration in countries' efforts to improve their standard of living.

Finally, we should note that our emphasis on the potential of fertility decline to spur economic growth is offered in the spirit of preventing future problems. Fertility decline certainly does not guarantee future economic growth. But it does pave the way for lessening the many problems that are exacerbated by having a large and rapidly growing population. 


\section{Appendix: Methodology}

Linking "meeting unmet need" (MUN) for contraception to the demographic dividend involves (a) estimating the impact of MUN on fertility trends and hence the population age structure, and (b) the impact of the population age structure on economic growth. We develop a model to estimate the impact of MUN on reduced fertility and to project a population age structure. We then use the approach described in Nigeria: the Next Generation (NNG) report (British Council Nigeria 2010) to estimate the demographic dividend and generate trends in per capita income from the projected population age structure.

\section{Meeting unmet need, fertility, and population age-structure (MUN-AFR model)}

We model the relationship between MUN and age-specific fertility rates (AFR) within five-year age groups of women, where women in each age group can use an age-specific method mix of contraceptives. The model takes as input the following data (data from Demographic and Health Surveys (DHS) indicated) and outputs a population age structure for the future, under different scenarios for levels of unmet need:

- Age-specific male and female populations in 2005.(United Nations 2011)

- Age-specific default fertility for years 2005-2050.(United Nations 2011)

- Age-specific mortality rates for 2010.(United Nations 2011)

- Fraction of women married or living with a male partner (DHS).

- Fraction of women demanding contraceptives ${ }^{5}$ (DHS).

- Fraction of women using contraceptives of a given type (e.g., pills, IUDs) (DHS).

- Typical-use efficacy of different contraceptive types.(Stover, Heaton and Ross 2006; Trussell 2011)

We implement this model for three countries: Kenya, Nigeria, and Senegal. The data sources for these countries are United Nations World Population Projections (WPP2010) (United Nations 2011) and Demographic and Health Surveys (DHS), supplemented with data from other sources (Stover, Heaton and Ross 2006; Trussell 2011). For DHS data, we choose the latest available data for each country (Kenya 2008-09) (Kenya National Bureau of Statistics (KNBS) and ICF Macro 2010), Nigeria 2008 (National Population Commission (NPC) [Nigeria] and ICF Macro 2009), and Senegal 2005 (Ndiaye and Ayad 2006) since the latest DHS data ${ }^{6}$ do not report contraceptive usage). For default fertility for each country from 2005-2050, we choose the highfertility variant from WPP2010 since even this variant would assume meeting some unmet need. We use this default fertility to infer age-specific fertility for women over 2005-2050, as if there were no contraceptive use, such that our projected population age structure approximately matches the WPP2010 population projection.

For each country, we explore four MUN scenarios: when none of the unmet need for contraception is met, which serves as our baseline $(B)$, when a low level $\left(1 / 3^{\text {rd }}\right)$ of unmet need is met $(L)$, a moderate level $\left(2 / 3^{\text {rd }}\right)$ of unmet need is met $(M)$, and a high level (all) of unmet need is met $(\mathrm{H})$. In exploring these scenarios, we assume that unmet need is met instantaneously, and at the same level across time. While this may seem unrealistic, the purpose of our investigation is not precision of population projections; rather, it is to establish the differences in these projections obtained under different MUN scenarios, which can reveal the differences in the demographic dividend. Making a consistent assumption across all scenarios is therefore

\footnotetext{
${ }^{5}$ The total demand for contraceptives, both for spacing and limiting births.

${ }^{6} 2008$ data.
} 
adequate. We also assume that all unmet need is filled through the current mix of modern methods.

\section{Population age structure and the demographic dividend}

We estimate the demographic dividend for each of the MUN scenarios in two steps: first, we estimate the historical determinants of per capita income growth using the empirical demographic dividend model that formed the basis for the NNG report (British Council Nigeria 2010); second, we use these determinants to project future per capita income growth using the demographic projections from the MUN-AFR model. The model in NNG expresses the per capita income growth rate over a five-year interval as a function of the following variables: per capita income and the working-age share of the population at the beginning of the interval, the difference in the growth rate between the working-age and total population over the interval, and a set of other control variables at the end of the interval. These other control variables include country-level indicators for tropical location, being landlocked, trade openness, average years of secondary schooling, life expectancy, and a measure of the quality of institutions in a country. Bloom et al. (Bloom et al. 2011) estimate the parameters of this model through a cross-country growth regression using five-year country-level panel data from 1965-2005 for a global sample of countries. For the simulations reported in this memo, we use the same dataset as that used in their paper, and estimate a specification very closely related to one of theirs.

Projecting the growth rate of per capita output in some future five-year interval requires projecting the above-mentioned determinants of that growth rate. Of these determinants, the MUN-AFR model provides all the demographic determinants of growth in all future periods for any MUN scenario - the working-age share of the population and the growth rates of the working-age and total populations. The year 2005 is the last year for which we have complete data on the control variables, so we make the simplifying assumption that these control variables stay at their 2005 values throughout all future periods in the projection. Though these are obviously not realistic, our primary interest is to estimate the variations in economic growth, rather than the absolute levels of such growth, under variations in age structure that are induced by different degrees to which unmet need is met. Holding the other determinants of growth fixed helps to isolate that impact.

With the above pieces in place, the projection of per capita income takes place step-by-step in five-year intervals, from 2005 onwards. We start with actual per capita income in 2005 and use the Bloom et al. demographic dividend model to project its growth rate from 2005 to 2010 . We combine this level and growth rate to determine income per capita in 2010 . The process is repeated for 2010-2015 and then onwards.

\section{Further notes on methodology}

In sensitivity analyses, we have confirmed that our results are robust to changes in several assumptions, e.g., the exact mix of methods used for contraception. We discuss three sets of assumptions in our model below. While discussing our assumptions, we also note that the purpose of our estimation was to determine the differences in benefits under various scenarios for meeting unmet need, rather than projecting the absolute level of benefits that would accrue under any given scenario.

\section{MUN-AFR model}

There are two assumptions of note in the MUN-AFR model. First, we assume mortality remains constant over time. This assumption was made only for simplifying the underlying model, and 
does not seem important as our population projections track the WPP projections well (which use time-varying mortalities) through 2050.

Second, we assume that the fraction of women who are married or in union, the fraction of women demanding contraceptives, and those using contraceptives remain constant over time. For the WPP2010 fertility variants, this assumption would imply that fertility reductions over time are happening because of reasons other than increasing contraceptive prevalence (CPR) (e.g., women marrying later because of rising education levels or lessening social pressures). This is unlikely to be true.

However, we have made the assumption of constant CPR for a pragmatic reason. First, to estimate the effect of meeting unmet need under a time trend for CPR would have required several other assumptions, for some of which little data would have been available. For example, for any given WPP2010 variant, we would have needed to infer an implied time trend in CPR compatible with this variant, and then guess the unmet need associated with this trend. This strategy would have involved assumptions, e.g., the method mix used over time, number of women married or in union in the future, the number of married or in-union women demanding contraceptives but not receiving them, etc. Since our interest was in the incremental benefit in per capita income (i.e., above the baseline) achieved by meeting unmet need, rather than absolute values of per capita income, we opted for the simplest set of assumptions that could give us broad estimates of the demographic dividend.

\section{Demographic dividend model}

A description of the data sources and the assumptions behind the data used for estimating historical economic growth can be found from the NNG report (British Council Nigeria 2010) and from (Bloom et al. 2011). Here we only note the differences in the estimation carried out here from what is in the report.

The principal difference in our estimation from that report is that we do not use time fixed effects or a time trend. We do this because the primary purpose of our estimation exercise here is projection into the future rather than parameter estimation. Using time fixed effects in the estimation would have required projecting the coefficients of future time dummies. Similarly, how to properly extrapolate a time trend into the future is unclear.

\section{Projecting future per capita income growth}

The first assumption of note in our model for projecting future growth in per capita income is that, for each country, we are assuming "all things equal". That is, we assume that all variables for a country remain fixed at their 2005 values (e.g., life expectancy, level of education, institutional quality), except for fertility and level of contraceptive use.

The projection of future economic growth due to demographic changes can become arbitrarily complicated if all conceivable factors that can influence this growth are included in the model. For instance, we can imagine that output per capita depends on labor force participation rates, labor participation by women, skill mix of the labor force, etc. Similarly, we know that that the demographic transition is accompanied by improvements in life expectancy, and we believe that realization of the demographic dividend in countries with weak institutions will require improvements in institutional capacity. But as before, we reasoned that any changes in such variables are likely to be similar across the baseline and MUN scenarios we are examining. In calculating the differential benefits across different 'meeting unmet need' scenarios and the baseline, we therefore kept these variables constant rather than introduce more assumptions 
into the mix. We think that parsimonious assumptions give us better understanding into how much the main drivers of economic growth influence the differences in income across different MUN scenarios.

The second assumption worth noting is that we assume future growth is solely determined by the variables that were historically associated with growth in a global sample of countries. The impact of this assumption on the difference in income across different MUN scenarios for a given country is not substantial, when the increase in per capita income for a MUN scenario in any year is viewed as a percentage of the baseline per capita income for that country. 


\section{References}

Ahmed, S., Q. Li, L. Liu, et al. (2012). "Maternal deaths averted by contraceptive use: an analysis of 172 countries." The Lancet 380(9837): 111-125.

Bloom, D., D. Canning and J. Sevilla (2003). The demographic dividend: a new perspective on the economic consequences of population change. Santa Monica, California, RAND Corporation. MR-1274.

Bloom, D. E. (2011). "7 Billion and Counting." Science 333(6042): 562-569.

Bloom, D. E. and D. Canning (2008). "Global demographic change: dimensions and economic significance." Population and Development Review 34 (suppl): 17-51.

Bloom, D. E., D. Canning, G. Fink, et al. (2007). "Realizing the Demographic Dividend: Is Africa Any Different?" African Economic Research Consortium.

Bloom, D. E., D. Canning and P. N. Malaney (2000). "Population Dynamics and Economic Growth in Asia." Population and Development Review 26: 257-290.

Bloom, D. E., J. Finlay, S. Humair, et al. (2011). "Prospects for economic growth in Nigeria: a demographic perspective." Demographic Research (under revision).

Bloom, D. E. and J. E. Finlay (2009). "Demographic Change and Economic Growth in Asia." Asian Economic Policy Review 4: 45-64.

Bloom, D. E. and J. Sachs (1998). "Geography, Demography, and Economic Growth in Africa." Brookings Papers on Economic Activity 2: 207-295.

Bloom, D. E. and J. G. Williamson (1998). "Demographic transitions and economic miracles in emerging Asia." World Bank Economic Review 12: 419-455.

Bongaarts, J. and S. Sinding (2011). "Population Policy in Transition in the Developing World." Science 333(6042): 574-576.

British Council Nigeria (2010). Nigeria: The Next Generation. David E. Bloom et. al., British Council Nigeria.

Canning, D. (2013). Demographic Dividend in Africa, World Bank (forthcoming).

Cleland, J., J. F. Phillips, S. Amin, et al. (1994). The Determinants of Reproductive Change in Bangladesh: Success in a Challenging Environment. Washington, DC, World Bank.

Gertler, P. and J. W. Molyneaux (1994). "How economic development and family planning programs combined to reduce Indonesian fertility." Demography 31(1): 33-63.

Kenya National Bureau of Statistics (KNBS) and ICF Macro (2010). Kenya Demographic and Health Survey 2008-09. Calverton, Maryland, KNBS and ICF Macro.

Lutz, W. and S. KC (2011). "Global Human Capital: Integrating Education and Population." Science 333(6042): 587-592.

Miller, G. (2010). "Contraception as Development? New Evidence from Family Planning in Colombia*." The Economic Journal 120(545): 709-736.

National Population Commission (NPC) [Nigeria] and ICF Macro (2009). Nigeria Demographic and Health Survey 2008. Abuja, Nigeria, National Population Commission and ICF Macro.

Ndiaye, S. and M. Ayad (2006). Enquête démographique et de santé au sénégal 2005. Calverton, Maryland, USA, Centre de Recherche pour le Développement Humain [Sénégal] et ORC Macro.

Nyonator, F. K., J. K. Awoonor-Williams, J. F. Phillips, et al. (2005). "The Ghana Communitybased Health Planning and Services Initiative for scaling up service delivery innovation." Health Policy and Planning 20(1): 25-34.

Pritchett, L. H. (1994). "Desired fertility and the impact of population policies." Population and Development Review 20(1): 1-55.

Schultz, P. (2009). "How Does Family Planning Promote Development? : Evidence from a Social Experiment in Matlab, Bangladesh, 1977 - 1996." from http://www.econ.yale.edu/ pschultz/TPS 1030 QJE.pdf. 
Singh, S. and J. E. Darroch (2012). Adding it up: costs and benefits of contraceptive services estimates for 2012. New York, NY, Guttmacher Institute.

Stover, J., L. Heaton and J. Ross (2006). "FamPlan: a computer program for projecting family planning requirements." from

http://www.healthpolicyinitiative.com/Publications/Documents/1256 1 FampmanE.pdf.

Trussell, J. (2011). "Contraceptive failure in the United States." Contraception 83(5): 397-404. UNFPA (2012). The State of World Population 2012. New York, United Nations Population Fund.

United Nations (2011). World population prospects: the 2010 revision. New York, NY, United Nations.

World Bank (2010). World development indicators 2010, World Bank.

World Bank (2013). World development indicators 2013, World Bank. 